\title{
Polished Aluminium Nitride Substrate Coated with Silicon Oxide Film
}

\author{
Yuji NAGAI and Nobumasa NAKAGAWA \\ Research and Development Laboratory, Toyo Aluminium K. K., 4-1, Aioi-cho, Yao-shi, Osaka 581 \\ シリコンオキサイドで被覆された研磨窒化アルミニウム基板 \\ 永井裕二・中川信政 \\ 東洋アルミニウム(株)研究開発本部研究所, 581 大阪府八尾市相生町 4-1
}

\begin{abstract}
Polished aluminium nitride substrates have imperfections of surface roughness in the form of cavities due to the loss of grains. Measurements using the Image Processing System and the Dimensional Measurement method, revealed that cavities with diameters larger than $10 \mu \mathrm{m}$ existed in quantities of about $22.5 \times 10^{5}$ pieces on a substrate of $152 \mathrm{~mm}^{2}$ and that their depths were about $1.3 \mu \mathrm{m}$. The cavities also had sharp edges and steep cliffs. The application of a thin coating of silicon oxide was studied for obtaining a smoother surface of the polished aluminium nitride substrate. The depth of the coated cavity decreased with increasing thickness of the film, and the shape of the cavities, especially their sharp edge and steep cliff could not be seen clearly as the thickness of the film increased. However, even if the film thickness was as great as $\mathbf{1 . 2}$ $\mu \mathrm{m}$, cavities of about $0.21 \mu \mathrm{m}$ depth remained on the coated substrate. A $10 \mu \mathrm{m}$ comb electric pattern could be made on the surface of the substrate coated with $0.5 \mu \mathrm{m}$ of film. All patterns exhibited 1856 blocks (a block has 29 lines) and were uniform without any broken portions.
\end{abstract}

[Received May 15, 1996; Accepted November 12, 1996]

Key-words : Aluminium nitride, Polished substrate, Silicon oxide, Planarization, Surface roughness, Coating, Circuit pattern, Thermal conductivity

1. Introduction

Aluminium nitride (AlN) has been used for power device substrate because of its high thermal conductivity, thermal expansion similar to that of a silicon chip and lower dielectric constant than alumina. ${ }^{1), 2)}$ Recently, AIN has been applied to multichip module (MCM) substrates.3),4) MCM substrates require a large size, $152 \mathrm{~mm}^{2}$ and $2 \mathrm{~mm}$ thick, for example, and a planar surface, since MCM is used as a board processor, and a microelectronic circuit requires the formation of ten-micron-wide line and space patterns on the surface of MCM substrates, for example. ${ }^{5)-7)}$

To obtain a planar surface of AlN substrates, mechanical polishing is generally used.8),9) Examination of the polished AlN substrates in this study revealed that some cavities appeared due to loss of grains. The results of measurements using the Image Processing System and the Dimensional Measurement method indicated that their diameters and depths were about $1-30 \mu \mathrm{m}$ and about $0.5-1.3 \mu \mathrm{m}$, respectively. Since the fine microelectronic circuit pattern is produced by depositing a metal material over the entire substrate by sputtering or vaporization and then patterning the thin metal film (less than $1.5 \mu \mathrm{m}$ ) by photolithography, if the substrate has some coarse surface roughness due to large and deep cavities produced by the polishing, the fine patterns cannot be fabricated. ${ }^{10)}$

In this study, the polished AlN substrates were coated with thin layers of silicon oxide (up to $1.2 \mu \mathrm{m}$ ) using a wet chemical method to overcome the above problem. ${ }^{11)}$ The relationship between the depth of the coated cavities and the thickness of the silicon oxide layer was studied. The effect of coating on the surface roughness was studied by making microelectronic circuit patterns on the coated substrates.

\section{Experimental procedures}

The AlN powder used was manufactured by Toyo Aluminium K.K. and had a $1.45 \mu \mathrm{m}$ average particle size and a $4.22 \mathrm{~m}^{2} / \mathrm{g}$ specific surface area. It contained 1.06 mass \% oxygen, 33.6 mass $\%$ nitrogen, 0.02 mass $\%$ carbon and less than $100 \mathrm{ppm}$ metal impurities. Five mass $\%$ yttrium oxide (99.9\% Mitsubishi Kasei Co., Ltd.) was used as a sintering aid. The particle size of the powder was $0.8 \mu \mathrm{m}$ according to the supplier.

Two types of AlN substrate were prepared by the tape casting method and the press method. Green sheets of the AlN substrates were prepared by tape casting. Slip formulations containing polymethyl methacrylate binder, phosphate ether dispersion agent, dibutyl phthalate plasticizer and IpA, MeK, toluene solvents were used. The thickness of the AlN tape was about $0.8 \mathrm{~mm}$. The three tapes were stacked to form a green sheet, $200 \times 200 \times 2.4 \mathrm{~mm}$ in size. Binder burnout was carried out at a heating rate of $3^{\circ} \mathrm{C} / \mathrm{min}$ to 500 and $500^{\circ} \mathrm{C}$ in air for $3 \mathrm{~h}$. Samples were placed on a $\mathrm{BN}$ setter and sintered in a furnace with a graphite heating element at $1850^{\circ} \mathrm{C}$ in nitrogen for $3 \mathrm{~h}$.

In the press method, the green bodies of substrates were prepared by uniaxial pressing using spray-dried powder. The powder was formed from the dried base mix by heatdrying using spray-dry equipment. The base mix formulations containing polyalkylmetacrylate binder, phosphate ether dispersion agent, dibutyl phthalate plasticizer and IpA, MeK and toluene solvents were used. The mean particle size of the powder was about $80 \mu \mathrm{m}$. The green bodies, $200 \times 200 \times 3 \mathrm{~mm}$, were fabricated by pressing under 98 $\mathrm{MPa}$ using a steel mold. Binder burnout for $5 \mathrm{~h}$ and sintering for $3 \mathrm{~h}$ were carried out using the same procedure as for the tape casting method.

Sintered samples were cut to $152 \times 152 \times 2 \mathrm{~mm}$ size substrates and their surfaces were polished mechanically by the manufacturer.

The size, number and distribution of cavities in the polished substrates were measured by the Image Processing System (Kawasaki Steel Corp.) using an optical microscope micrograph of the substrates. The depth of cavities was also measured by the Dimensional Measurement method ${ }^{12), 13)}$ using two scanning electron micrographs (SEM) taken at different angles.

Silicon oxide coatings were realized by coating an alcohol 
solution of methyl siloxane (SOG 512 Allied Signal Inc.) ${ }^{14)-17)}$ onto the substrates using a spin coater developed for large substrates (Cup Type TR 11000, Tokyo Electron Ltd.) at $500 \mathrm{rpm}$ for $2 \mathrm{~s}$ and continuously at 2000 rpm for $5 \mathrm{~s}$. Each coating was dried and baked in an oven at $80^{\circ} \mathrm{C}$ for $60 \mathrm{~s}, 150^{\circ} \mathrm{C}$ for a further $60 \mathrm{~s}$ and then $200^{\circ} \mathrm{C}$ for $60 \mathrm{~s}$ in air. After preheating, the samples were baked at $450^{\circ} \mathrm{C}$ for $45 \mathrm{~min}$ and then further cured at $850^{\circ} \mathrm{C}$ for $30 \mathrm{~min}$ to change the layer to pure silicon oxide. The thickness of the layer was adjusted by varying the number of coatings.

\section{Results and discussion}

Figure 1 shows SEM micrographs of the surface of (a) a tape casting substrate and (b) a pressed one. The surfaces of both substrates exhibited some imperfections such as voids and cavities due to the loss of grains. The grain-boundary of the substrate made by tape casting was observed clearly in comparison with the pressed one. It is clear that the surface status of polished AlN substrates depends on the fabrication method of green bodies. In both substrates, there was some yttrium oxide (shown as white spots in the
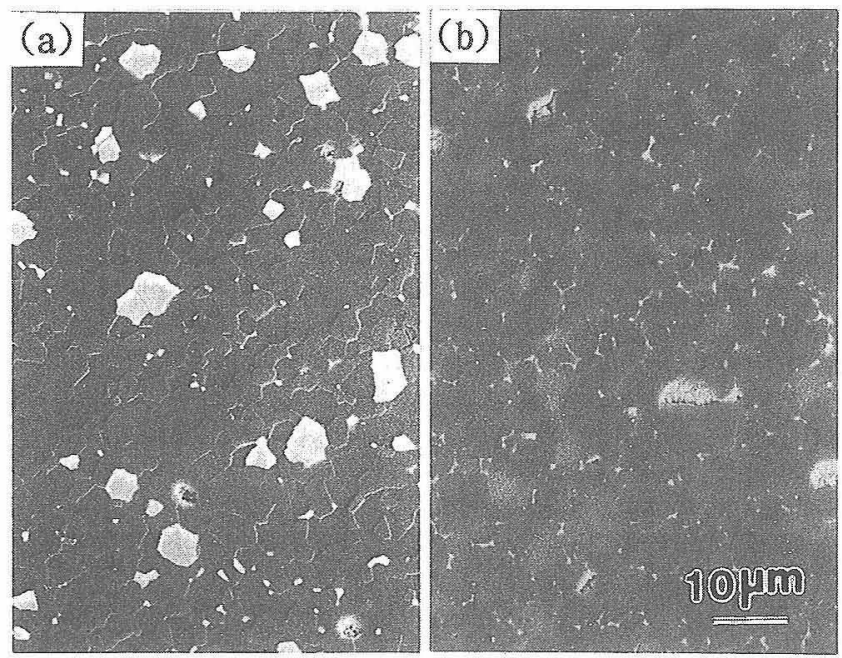

Fig. 1. Surface of a polished AlN substrate. (a) Substrate made by the tape casting method. (b) Substrate made by the press method.
SEM micrograph).

Figure 2 shows the relationship between the distribution of imperfections (cavities) appearing at the surfaces of the polished substrates and their size. Five portions, near the four corners and the center of the substrate, were selected in order to measure the cavities. The area of each portion was $0.1 \times 0.1 \mathrm{~mm}$. The number of cavities shown in Fig. 2 was calculated by Heywood diameter and indicates the total number of the five portions. Fifteen polished substrates produced by each method were prepared for this study and three substrates were selected from among them for evaluation. Figure 2 indicates that the surfaces of both substrates exhibited many cavities of $1-23 \mu \mathrm{m}$ in diameter and that the tape casting substrates have a large number of cavities of 1 $\mu \mathrm{m}$ in size but the press substrates have a large number cavities of 1.2 or $2.0 \mu \mathrm{m}$. Both substrates have cavities larger than ten micro-meter in diameter in three to five pieces of the measured area. From the results, it can be calculated that cavities with diameters larger than ten micro-meter from $13.5 \times 10^{5}$ to $22.5 \times 10^{5}$ pieces exist in a surface area of $152 \times 152 \mathrm{~mm}$ (a piece of substrate).

Figure 3 shows SEM micrographs of some large cavities which appeared at (a) and ( $\left.a^{\prime}\right)$ the surface of the tape casting substrate and (b) and ( $\left.b^{\prime}\right)$ the press substrate. The SEM micrographs were taken at two different angles, $0^{\circ}$ tilt and $15^{\circ}$ tilt, respectively. From Fig. 3 , it can be seen that there are cavities from about 2 to $6 \mu \mathrm{m}$ in diameter at the surface of the tape casting substrate and from about 5 to 10 $\mu \mathrm{m}$ at the press substrate. These cavities are deep and have sharp edges and steep cliffs. These cavities are adjacent and influence the formation of microelectronic circuit patterns as a larger cavity.

The depth of the cavities appearing at the surface of polished substrates can be measured and calculated using a stereopair of micrographs based on the Dimensional Measurement method.12),13) Using stereoscope glasses, a stereopair of micrographs was obtained from the two different tilted SEM micrographs. The $0^{\circ}$ and $15^{\circ}$ tilt SEMs were used in the study. Observing the stereopair micrographs, a point is marked at the top portion of the cavity and at the bottom portion on each SEM micrograph and a right triangle is constructed on each micrograph by connecting three points including the marked two points shown in Figs. 4 and 5. From this construction, two right angled triangles are prepared on each SEM micrograph one by one. Figure 4
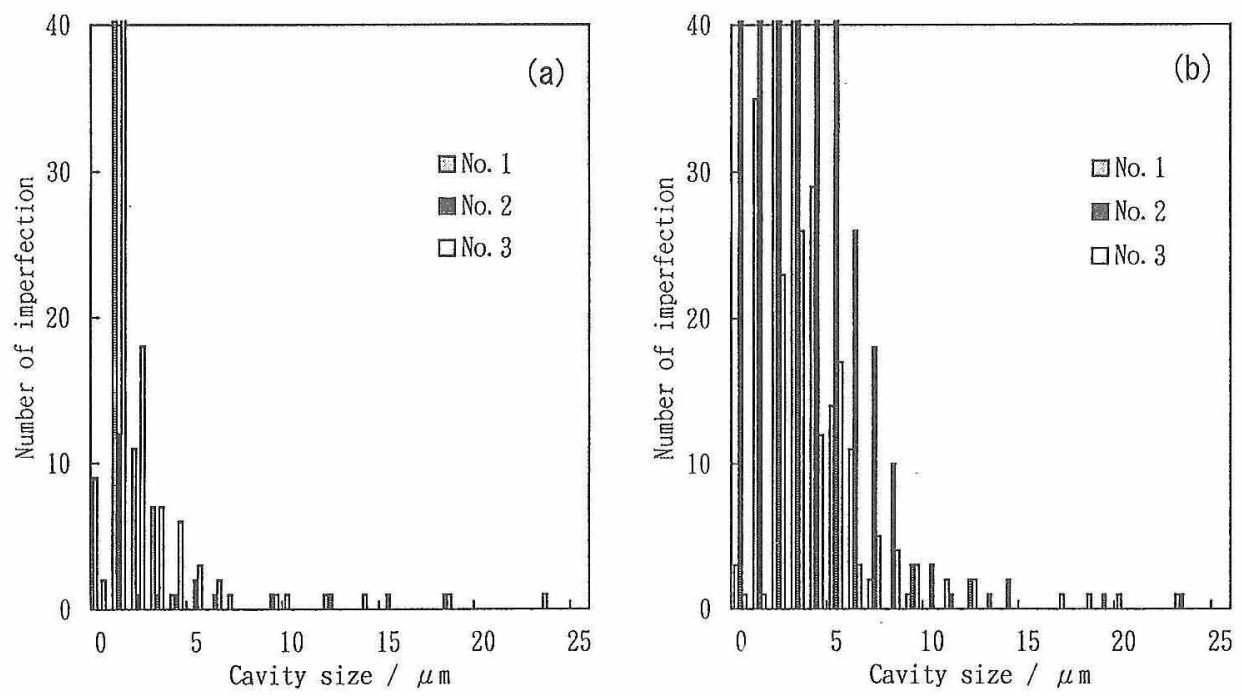

Fig. 2. Distribution of imperfections (cavities) appearing on the surface of a polished AlN substrate. (a) Substrate made by the tape-casting method. (b) Substrate made by the press method. 

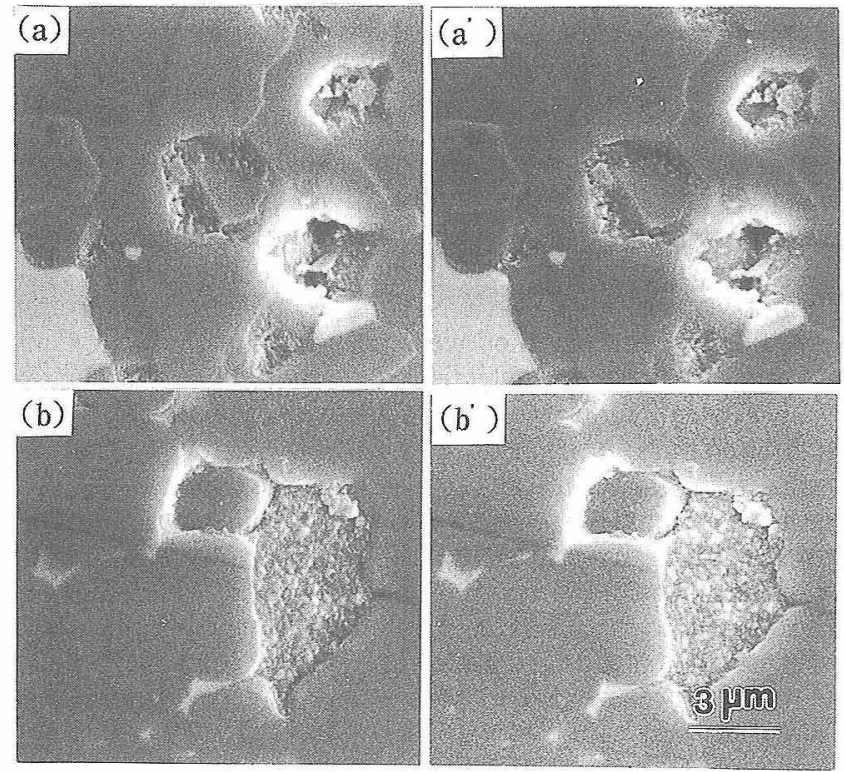

Fig. 3. SEM micrograph of large cavities. (a) and ( $a^{\prime}$ ) Substrate made by the tape casting method. (b) and ( $b^{\prime}$ ) Substrate made by the press method. (a) and (b) SEM micrograph at $15^{\circ}$ tilt. ( $\mathrm{a}^{\prime}$ ) and (b') SEM micrograph at $0^{\circ}$ tilt.
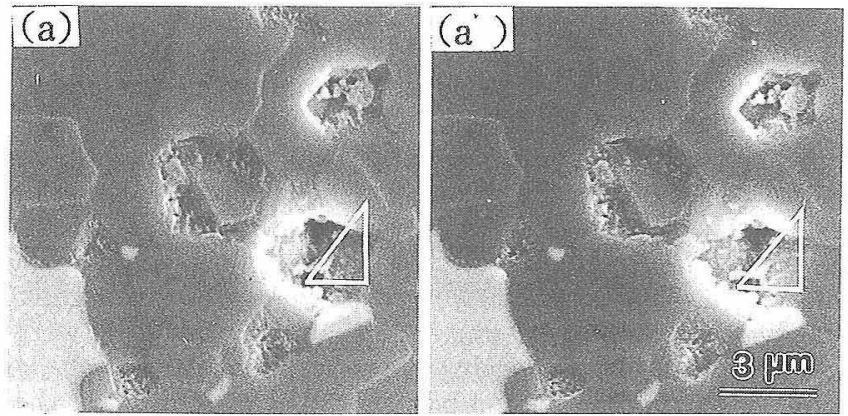

Fig. 4. Drawings of a right angled triangle for measuring the depth of a cavity. (a) SEM micrograph (15 tilt). (a') SEM micrograph $\left(0^{\circ}\right.$ tilt $)$. (a) and $\left(a^{\prime}\right)$ Substrate made by the tape-casting method.

shows an example of a right angled triangle constructed on the SEM micrographs. Figure 5 shows the construction method of right angled triangles.

Using the numerical value shown in Fig. 5 , the depth of the cavities can be measured using the following expression. 12),13)

$$
D=\left(\frac{a \cos \theta}{\sin \Phi}-\frac{b \cos \theta^{\prime}}{\tan \Phi}\right) \times \frac{1}{M}
$$

where

$D=$ depth of cavity,

$\Phi=$ absolute value of tilted angle,

$\theta=$ actual angle of micrograph tilted $15^{\circ}$,

$\theta^{\prime}=$ actual angle of standard micrograph $0^{\circ}$,

$M=$ magnification of micrograph.

In this study, the value of $\Phi$ is $15^{\circ}$.

The depth of a cavity in a substrate was calculated by Eq. (1). The results of calculation indicate that the depth of the cavity of the tape casting substrate is $1.26 \mu \mathrm{m}$ and that of cavities of the press substrate is 0.62 or $0.74 \mu \mathrm{m}$ (Fig. 3 ). The results shown in Figs. 2 and 3 indicate that the polished substrate has several cavities larger than $10 \mu \mathrm{m}$ in size and 0.62 to $1.26 \mu \mathrm{m}$ in depth.
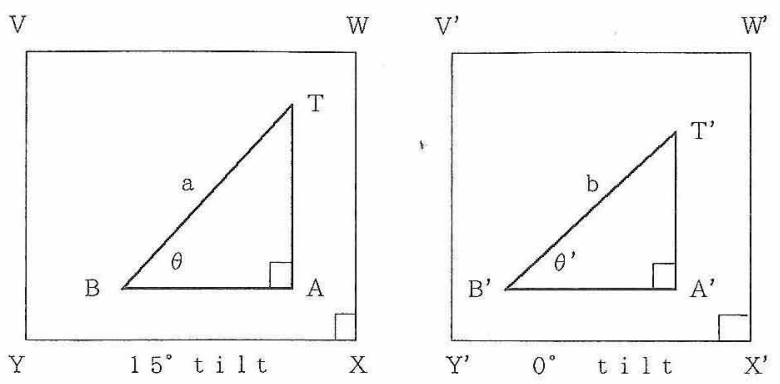

Square WiXY: Micrograph $\left(15^{\circ}\right.$ tilt)

Square $V^{\prime} W^{\prime} X^{\prime} Y^{\prime}:$ Micrograph $\left(0^{\circ}\right.$ tilt $)$

T: Marked point of top of cavity

T': Marked point of top of cavity

B: Marked point of bottom of cavity

B' : Marked point of botton of cavity

$\mathrm{T}, \mathrm{B}, \mathrm{A}$ : Vertices of triangle

$T^{\prime}, B^{\prime}, A^{\prime}$ : Vertices of triangle

Where, triangle TBA

Where, triangle T' $\mathrm{B}^{\prime} \mathrm{A}^{\prime}$

$\overline{\mathrm{BA}} / \overline{\mathrm{YX}}, \overline{\mathrm{TA}} / \overline{\mathrm{WX}}$

a: Hypotenuse

$\overline{B^{\prime} A^{\prime}} / \overline{Y^{\prime} X^{\prime}}, \overline{T^{\prime} A^{\prime}} / \overline{W^{\prime} X^{\prime}}$

$\theta$ : Angle TBA

b: Hypotenuse

$\theta^{\prime}$ : Angle $\mathrm{T}^{\prime} \mathrm{B}^{\prime} \mathrm{A}^{\prime}$

Fig. 5. Drawing of right angled triangles for calculating the depth of the cavities. (left) Drawing for SEM micrograph ( $15^{\circ}$ tilt). (right) Drawing for SEM micrograph ( $0^{\circ}$ tilt).

For use in MCMI, the application of fine circuit patterns, less than $1.5 \mu \mathrm{m}$ in thickness and $10 \mu \mathrm{m}$ in width, is being attempted. An aluminium or copper metal is mainly studied as the material for the patterns. ${ }^{6}$ ) Generally, the fine pattern is produced by depositing a metal material over the entire substrate by sputtering or vaporization and then patterning the thin metal film by photo-lithography. If the above cavities exist on the surface of the substrate, it is impossible to form a uniform and continuous metal film. Furthermore, since the large polished substrate has a lot of cavities of about $1.3 \mu \mathrm{m}$ in depth on its surface, the fine microelectronic circuit pattern cannot be formed over its entire surface either. The cavities of the substrate must be filled with silicon oxide and planed in order to form a fine circuit pattern on it.

Figure 6 shows the cavity coated with a $0.4-\mu \mathrm{m}$-thick silicon oxide film for the tape casting substrate. The results of FT-IR and X-ray analysis indicated that the film consisted of only silicon oxide and was in an amorphous state. ${ }^{10)}$ This coated cavity was about $12 \mu \mathrm{m}$ in diameter and $0.95 \mu \mathrm{m}$ in depth. The silicon oxide film could not fill the cavity perfectly and the cavity is still deep. Moreover, the film covered all portions of the cavity and its edge became round. After removing the silicon oxide film using hydrofluoric acid, the depth of the original cavity was measured to be $1.28 \mu \mathrm{m}$.

From the values of 1.28 and $0.95 \mu \mathrm{m}$, the actual thickness of the coated film is calculated to be $0.33 \mu \mathrm{m}$ and $0.33 \mu \mathrm{m}$ is nearly equal to the $0.4 \mu \mathrm{m}$ in thickness of the coating film. From the result, it is judged that there is no difference between the actual thickness of the coated film and the target thickness of the coating film.

SEM micrographs of the cavity coated with $0.5 \mu \mathrm{m}$ of film and $0.8 \mu \mathrm{m}$ of film are shown in Figs. 7 and 8, respectively. The tape casting substrates were also used. In Figs. 7 and 8 , the film covered the surface of the cavities but could not fill the cavities completely to produce planar substrates without surface roughness. The depth of the cavity coated with $0.5 \mu \mathrm{m}$ of film was reduced from $1.21 \mu \mathrm{m}$ (original depth) to $0.68 \mu \mathrm{m}$ (Fig. 7) and with $0.8 \mu \mathrm{m}$ of film was reduced from $1.18 \mu \mathrm{m}$ to $0.42 \mu \mathrm{m}$ (Fig. 8 ). The cavities still 


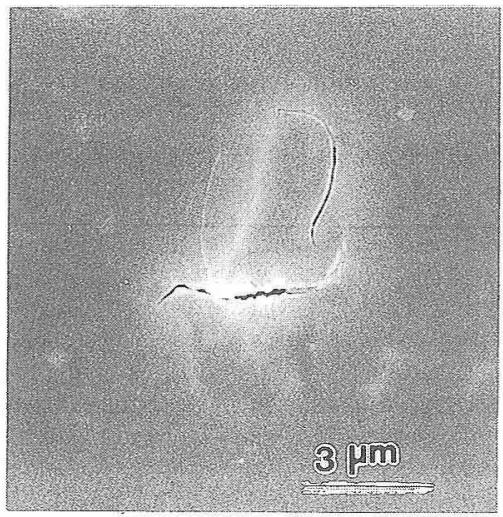

Fig. 6

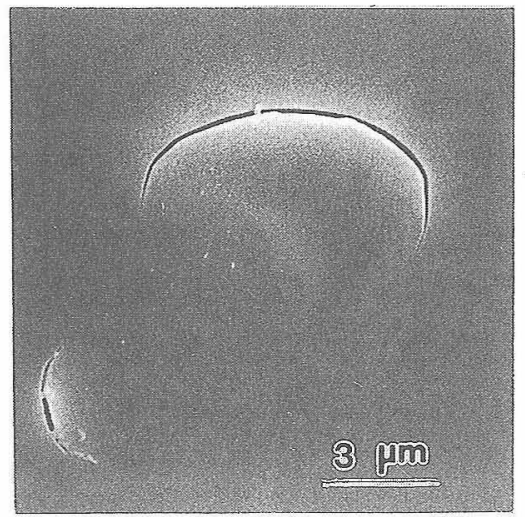

Fig. 7

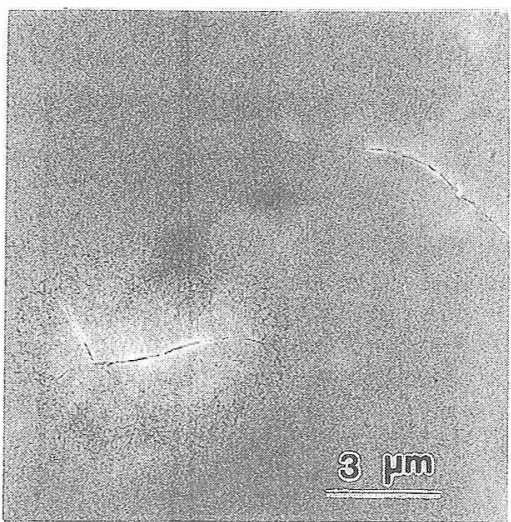

Fig. 8

Fig. 6. SEM micrograph of a cavity coated with a $0.4-\mu \mathrm{m}-$ thick film. Used tape casting substrate.

Fig. 7. SEM micrograph of a cavity coated with a $0.5-\mu \mathrm{m}$-thick film. Used tape casting substrate.

Fig. 8. SEM micrograph of a cavity coated with a $0.8-\mu$ m-thick film. Used tape casting substrate.

have some depth with each coating. However, the inclination of the slope of the cavities becomes less sharp and, particularly, the edges of the cavities become rounded. From Figs. 6,7 and 8 , the depth of the coated cavities decreases with increasing thickness of the film. Then, increasing the film thickness to $1.2 \mu \mathrm{m}$, the coating was carried out. The depth of the coated cavity decreased from 1.32 to $0.21 \mu \mathrm{m}$. However, some depth still remained on the coated substrate and a planar surface could not be obtained either.

One or two cracks appeared in the film of the coated cavity for the evaluated substrates. The appearance of cracks is affected by the coating condition of the siloxane solution and, in particular, the heat treatment condition. The film without cracks is obtained by slow heat treatment.

The fine comb pattern made on the coated substrate is shown in Fig. 9. Figure 9 (a) shows an optical microscope photgraph of one block of the fine pattern and (b) is the magnified fine pattern made on the coated cavity. This cavity was about $12 \mu \mathrm{m}$ in diameter. Both of the fine patterns have $10-\mu \mathrm{m}$-wide lines and spaces. A substrate coated with $0.5 \mu \mathrm{m}$ of film was used for this experiment. The fine patterns were made by dry sputtering using a mask and were composed of three types of metal. Their constitutions were as follows : $\mathrm{Cr}-\mathrm{Pd}-\mathrm{Au}=0.1-0.2-0.1 \mu \mathrm{m}$.

The 1856 blocks of the fine patterns were made on the coated large substrate $(152 \times 152 \mathrm{~mm})$ and a block has 29 lines. It was observed by visual inspection using an optical microscope that all patterns were uniform without any broken portions.

The photograph of Fig. 9 (b) indicates that if the large,
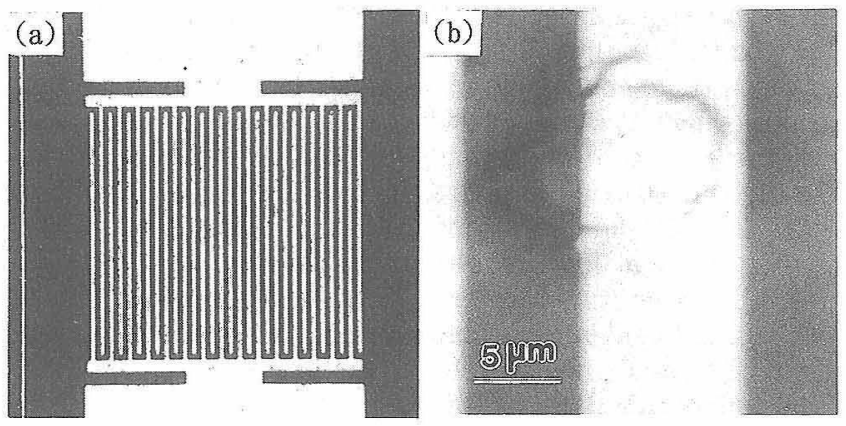

Fig. 9. Optical micrograph of a comb microelectronic pattern made on the surface of a coated AlN substrate. (a) A block of microelectronic patterns. (b) A portion of a line of a microelectronic pattern made on the surface of a cavity coated with a $0.5 \mu \mathrm{m}$ film. deep cavity, caused by mechanical polishing is coated and covered with thin silicon oxide film, the fine pattern with $10-\mu \mathrm{m}$-wide lines and spaces can be formed on the surface of a large substrate.

From the results of this study, the use of silicon oxide coating is concluded to be an effective method for formation of a fine pattern of $10-\mu \mathrm{m}$-wide lines and spaces on the surface of large polished AIN substrates. This method can be applied very simply to the progressive miniaturization of MCM.

\section{Conclusion}

A large size AlN substrate, $152 \times 152 \times 2 \mathrm{~mm}$, was prepared in this study by sintering, and polished mechanically to obtain a planar surface. A lot of cavities due to the loss of grains appeared on the surface of the substrate. The results of the Image Processing System analysis indicated that the diameter of their cavities was distributed broadly from 1 to $23 \mu \mathrm{m}$ and, in particular, three or five cavities of larger than $10 \mu \mathrm{m}$ in diameter were observed in the measured area. From the results, it can be estimated that cavities of larger than $10 \mu \mathrm{m}$ in diameter exist on the surface of large substrates from $13.5 \times 10^{5}$ to $22.5 \times 10^{5}$ pieces. It is clear that there are a lot of cavities on the surface of polished AlN substrates.

The result of the Dimensional Measurement method conducted using stereopair micrographs revealed that the depth of the cavities was from 0.62 to $1.32 \mu \mathrm{m}$ and that these cavities had a sharp edge and a steep cliff.

When the surfaces of the polished substrate were coated with silicon oxide film, the film filled and covered the cavities but could not fill them perfectly so that the cavities still had some depth. The depth of the coated cavity was decreased by increasing the thickness of the film, and the shape of the cavity, especially the sharp edge of the cavity, could not be seen clearly as the thickness of film increased. The depth of the cavity decreased from 1.32 to $0.21 \mu \mathrm{m}$ at around the maximum film coating thickness of $1.2 \mu \mathrm{m}$ but remained on the surface of the coated substrate. However, the sharp edge, steep cliff and shape of the cavity disappeared and the cavity became nearly flat.

A fine pattern of $10-\mu \mathrm{m}$-wide lines and spaces could be formed on the surface of large AlN substrates coated with $0.5 \mu \mathrm{m}$ of film, and all patterns of 1856 blocks were uniform without any broken portions. A block was constituted of 29 lines. 


\section{References}

1) L. M. Sheppard, Am. Ceram. Soc. Bull., 69, 1810-12 (1990).

2) A. Nazwri and M. Kahn, Am. Ceram. Soc. Bull., 72, 59-65 (1993).

3) T. Kohara, Shingaku Giho ICD92-126, 92, 1-8 (1992).

4) K. Nakamura and K. Nagahiro, Nikkei Microdevices, April, 24-41 (1993)

5) A. Kimura, T. Tsujimura, K. Saitoh and Y. Kohno, Proceedings of 1st International Conference on Multichip Modules., Denver (1992) pp. 23-27.

6) D. Bursky, Electronic Design., July, 99-100 (1992).

7) M. F. Bregman, Proceedings of 7th International Microelectronics Conference, Yokohama (1992) pp. 30-36.

8) Y. Takahashi, M. Kikuchi, S. Suzuki and T. Suga, Seramikkusu Ronbunshi, 99, 613-19 (1991).

9) Y. Takahashi, K. Okano, S. Suzuki and T. Suga, J. Ceram.
Soc. Japan, 100, 675-79 (1992).

10) Y. Nagai, J. Ceram. Soc. Japan, 104, 719-22 (1996).

11) T. Kuromitu, H. Yoshida and K. Morinaga, Proc. Annual Meet. Ceram. Soc. Japan (1988) p. 25.

12) S. Kimoto, T. Suganuma and T. Oshima, Shashin Sokuryou, 8, 8-12 (1969).

13) J. W. S. Hearle, J. T. Sparrow and P. M. Cross, "The Use of the Scanning Electron Microscope”, Pergamon Press (1972) pp. 219-26.

14) S. Morimoto and S. Q. Grant, IEEE VMIC Conf., Santa Clara (1988) pp. 411-18.

15) M. Kawasaki, K. Matsuda, K. Miki and K. Sakiyama, IEEE VMIC Conf., Santa Clara (1988) pp. 419-25.

16) P. Chiang and D. B. Fraser, IEEE MVIC Conf., Santa Clara (1989) pp. 397-403.

17) Y. Numazawa, Semiconductor World, March, 185-89 (1991). 